\title{
BMJ Open Development of the Prevent for Work Questionnaire (P4Wq) for the assessment of musculoskeletal risk factors in the workplace: part 2-pilot study for questionnaire development and validation
}

\author{
Francesco Langella (D) , ${ }^{1}$ Daniele Vanni, ${ }^{1}$ Morten Høgh, ${ }^{2}$ \\ Thorvaldur Skuli Palsson (10) ,' Steffan Wittrup McPhee Christensen, ${ }^{2,3}$ \\ Pablo Bellosta-López (1) ," Jorge Hugo Villafañe (1) ," Palle Schlott Jensen, ${ }^{3}$ \\ Priscila de Brito Silva (1) , ${ }^{3}$ Pablo Herrero (1) , ${ }^{6}$ Paolo Barletta, ${ }^{1}$ \\ Victor Domenéch-García (D) , ${ }^{4}$ Pedro Berjano, ${ }^{1}$ On behalf of the Prevent for Work \\ Study Group
}

To cite: Langella F, Vanni D, Høgh M, et al. Development of the Prevent for Work Questionnaire (P4Wq) for the assessment of musculoskeletal risk factors in the workplace: part 2-pilot study for questionnaire development and validation. BMJ Open 2021;11:e053988. doi:10.1136/ bmjopen-2021-053988

- Prepublication history and additional supplemental material for this paper are available online. To view these files, please visit the journal online (http://dx.doi.org/10.1136/ bmjopen-2021-053988).

Received 30 May 2021 Accepted 25 November 2021

\section{Check for updates}

(c) Author(s) (or their employer(s)) 2021. Re-use permitted under CC BY-NC. No commercial re-use. See rights and permissions. Published by BMJ.

For numbered affiliations see end of article.

\section{Correspondence to} Dr Francesco Langella; francesco.langella.md@gmail. com

\section{ABSTRACT}

Objective The aim of this study was to develop a multifactorial, self-report questionnaire: Prevent for Work Questionnaire (P4Wq). The questionnaire is intended for screening for risk factors in work-related musculoskeletal disorders (WMSDs).

Design Data were collected from otherwise healthy workers employed in three service areas at a specialist hospital in Italy: healthcare, administration and ancillary services.

Setting and participants In all, 115 participants were enrolled (67\% women; average age $41.5 \pm 9.94$ years). The content of the tool for WMSDs was derived from three participation rounds of analysis involving a select group of experts who identified the questionnaire domains and items. Participants responded to 89 items in addition to the EuroQol 5 Dimensions Questionnaire (EQ-5D-5L), Fear-Avoidance Beliefs Questionnaire (FABq) and 0swestry Disability Index (ODI). The proportion of missing data and the distribution of responses were analysed for each item. Items with a discrimination index $>0.40$ and an interitem correlation $<0.80$ were retained. Factor analysis was performed using the VARIMAX rotation method, factor extraction, and identification, assignment of items to subscales, and assignment of scores to items. Internal consistency, reliability, construct validity and face validity were also assessed.

Results A total of 52 items were included in the factor analysis and four subscales identified: Physical Stress Subscore (six items); Mental Stress Subscore (six items); Job Satisfaction Subscore (four items) and Kinesiophobia/ Catastrophizing Subscore (four items). The items in the final questionnaire version had a factor loading $>0.7$. The questionnaire consisted of 20 items with good internal consistency (Cronbach's alpha 0.81-0.91), reliability (weighted kappa coefficient 0.617-1.00), good construct

\section{Strengths and limitations of this study}

- The development of the self-administered Prevent for Work Questionnaire (P4Wq) was based on the biopsychosocial nature of chronic musculoskeletal pain.

- The P4Wq was tested in hospital workers from three areas: healthcare, administration and ancillary services.

- For this single-centre study, participation was voluntary, which may limit its generalisability.

- The predictive capabilities of the P4Wq to inform educational content and to identify the occurrence of WMSDs or their progression to chronicity require further investigation via high-quality studies with longer follow-up periods.

validity (EQ-5D-5L, $r=-0.549, p<0.001 ; 0 D I, r=0.549$, $\mathrm{p}<0.001$; FABq work, $\mathrm{r}=0.688, \mathrm{p}<0.001$ ) and satisfactory face validity (universal validity index $96.04 \%$ ).

Conclusion The P4Wq is a 20 -item, multifactorial self-report risk assessment questionnaire. It may provide a useful tool for screening for WMSDs by specifically addressing back disorders. It investigates risks for individual workers and may inform educational programmes and preventive strategies tailored to a worker's needs.

Trial registration number NCT04192604

\section{INTRODUCTION}

Work-related musculoskeletal disorders (WMSDs) refer to damage to muscles, bones, joints and soft tissues associated with exposure to risk factors in the workplace. ${ }^{1}$ WMSDs 
range from mild, transitory disorders to chronic conditions if they persist for more than 12 weeks. ${ }^{2}$ The European Agency for Safety and Health at Work (EU-OSHA) states that WMSDs are an increasing burden for Western societies. ${ }^{3}$ For example, the Sixth European Working Conditions Survey reported a twofold increase in WMSDs of the spine and upper limbs in the last decade, accounting for half of employees' complaints. ${ }^{4}$ In Europe, WMSDs are the most frequent occupational disorder and a major driver of healthcare costs. ${ }^{3}$ WMSD-related costs are estimated at $2 \%$ of the gross domestic product in the European Union $(\mathrm{EU})^{5}$ and $50 \%$ of the costs of all workrelated health issues. ${ }^{6}$ In addition, WMSDs are responsible for half of the days of absenteeism lasting for more than 3 days, $49 \%$ of absenteeism lasting 2 weeks or more, and about $60 \%$ of cases of permanent work disability. ${ }^{7}$

WMSDs refer to musculoskeletal disorders in which multiple factors related to work activity, workplace environment and worker performance contribute to a varying extent to pain and disability. Physical stressors, ${ }^{8}$ work stress, pain beliefs and sleep disturbances all seem to play a key role in the development of WMSDs, ${ }^{9}$ loss of work productivity and absenteeism. ${ }^{10}$ Research models have shown that stressful work environment, ${ }^{11}$ mental stress ${ }^{12}$ and fear-avoidance are closely linked to work-related disability and its progression to chronicity.

According to the EU-OSHA, ${ }^{3}$ successfully managing WMSDs relies on prevention, early intervention and promotion of good musculoskeletal health in the workplace. The earlier the problem is identified, the better it can be addressed in clinical practice. A tool that integrates a multifaceted model seems ideal for combining the strengths of medicine, public health and psychology to optimise early diagnosis and management of WMSD and to identify operational steps in the prevention of WMSDs. ${ }^{13}$

Current medical evidence suggests that clinical interventions can reduce disability and absenteeism related to WMSDs. ${ }^{14}$ A multidisciplinary approach can provide a critical starting point for achieving good outcomes. ${ }^{15}$ Early diagnosis, psychosocial interventions ${ }^{16}$ workplace factor management ${ }^{17}$ and education in preventing musculoskeletal pain ${ }^{18}$ have reduced the incidence of WMSDs and related absenteeism.

The literature suggests that the risk of developing WMSDs and their progression to chronicity may be captured by a questionnaire investigating physical and psychosocial domains, including a biopsychosocial model of disease and fear-avoidance components of chronic pain. ${ }^{19}$ With this in mind, the primary aim of this study was to develop a multifactorial self-administered questionnaire (Prevent for Work Questionnaire $(\mathrm{P} 4 \mathrm{Wq})$ ) to investigate risk factors for WMSDs. The secondary objective was to compare the psychometric properties of the $\mathrm{P} 4 \mathrm{Wq}$ against previously developed questionnaires to determine the construct behaviour of its final version. The psychometric properties of pain/discomfort, anxiety and depression were tested using the EuroQol
5 Dimensions Questionnaire (EQ-5D-5L), ${ }^{20}$ while fearavoidance behaviour was tested with the Fear-Avoidance Beliefs Questionnaire (FABq) ${ }^{21}$

\section{METHODS}

\section{Study setting and population}

This pilot study was conducted on behalf of the Prevent for Work Project funded by the European Commission within the EU Erasmus+ Programme. The study's primary aim was to develop a multifactorial, self-report risk assessment questionnaire for WMSDs and assess its psychometric properties. The sample size was set at 115 participants according to a previous study on the same topic. ${ }^{22}$ The study was conducted at the IRCCS Istituto Ortopedico Galeazzi (IOG), Milan, Italy. The IOG is a research hospital that provides specialised, advanced orthopaedic care. It employs more than 1000 workers engaged in a variety of physically demanding tasks that may cause physical discomfort or pain.

Inclusion criteria were: ability to read and understand Italian and at least 1 year of work at the IOG. Exclusion criteria were: previous surgery for musculoskeletal disorders, musculoskeletal conditions (eg, fibromyalgia, arthritis, ankylosing spondylitis) or others that result in lasting disability or absence from work. The study participants worked in one of three areas: healthcare (physicians, nurses, radiology technicians, physiotherapists), administration (laboratory researchers, concept employees, video terminal workers), other ancillary services (maintenance, neurophysiopathology or orthopaedic technicians). Enrolment for each worker category was done using convenience sampling and interrupted when it reached $40 \%$ of the total sample; this was done to limit maximum possible inhomogeneity (of the whole cohort) and not exceed the proportions $40 \%-40 \%-20 \%$.

This study followed the standards and criteria defined by the Strengthening the Reporting of Observational Studies in Epidemiology statement: guidelines for reporting observational studies. ${ }^{23}$ The questionnaire development process began with a literature review and a Delphi study to identify domains and items for the pilot study. ${ }^{19}$ PBerjano and FL designed the project for P4Wq development by following standards and criteria defined by the Consensus-based Standards for the selection of health Measurement INstruments guidelines for content validity evaluation of patient-reported outcome measures (PROMs). ${ }^{24}$ Figure 1 illustrates parts one and two of the workflow of questionnaire development.

\section{Content validity}

In January 2020, a literature review was conducted to identify previously described risk factors and diagnostic and prognostic tools to assess WMSDs and their risk factors. The study group first identified all possible aspects needed to develop an evidence-based WMSDs risk assessment questionnaire: demographics, socioeconomic 
Process Development Prevent 4 Work questionnaire

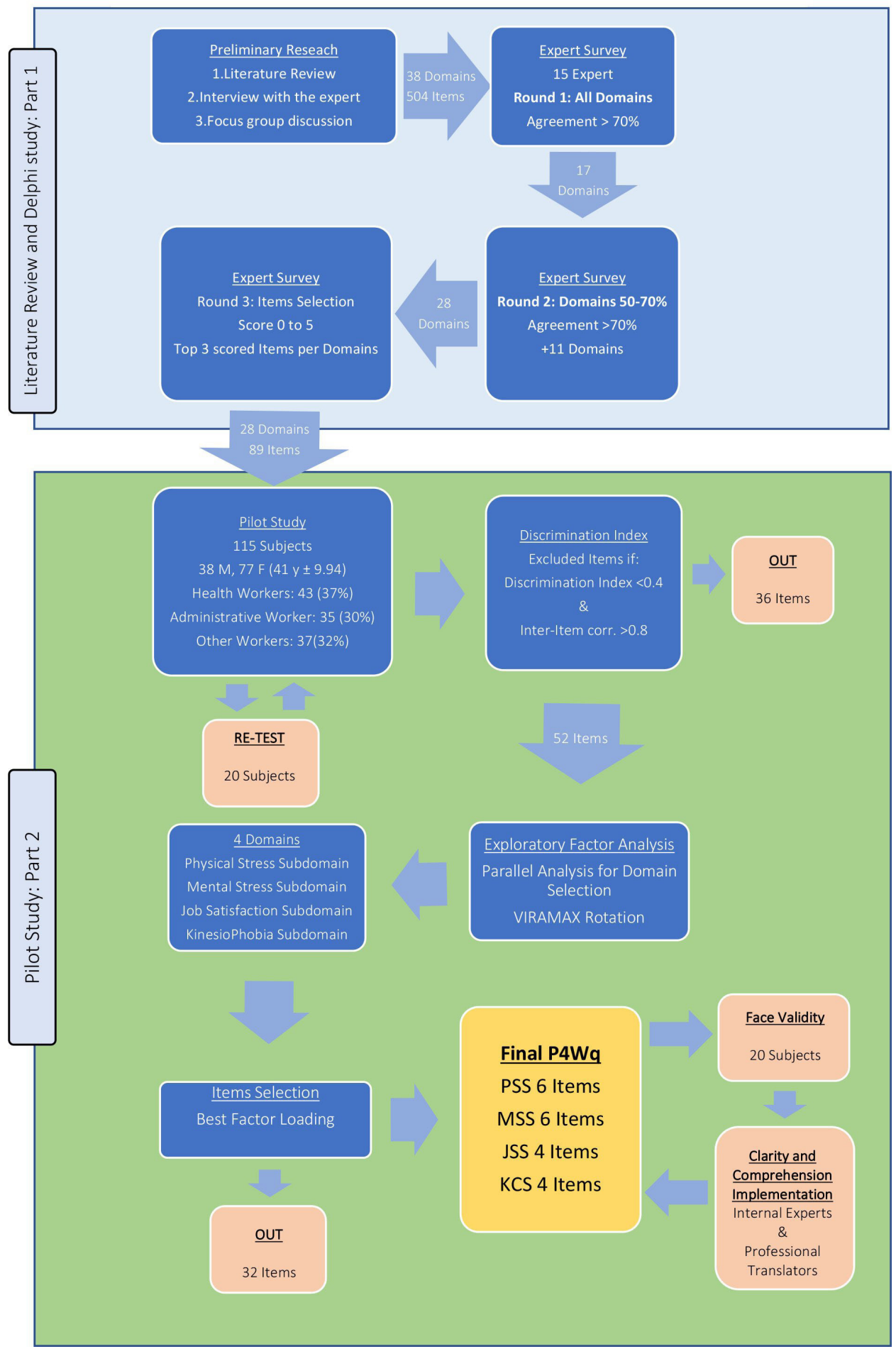

Figure 1 Overview of the workflow of the literature review and the Delphi process for the pilot study. JSS, Job Satisfaction Subscore; KCS, Kinesiophobia/Catastrophizing Subscore; MSS, Mental Stress Subscore; PSS, Physical Stress Subscore.

environment, health status, job position and quality of life. This identified questionnaires for the evaluation and stratification of the population based on the quality of life, disability and work-related pain beliefs.

A Delphi group of 15 experts in WMSDs was formed to define appropriate domains and items identified in the initial literature research. The initial WMSDs risk assessment questionnaire was developed based on 89 selected items in 28 domains that covered two factors. ${ }^{19}$ The items and domains identified in the expert analysis moved into the pilot study phase after full approval of the contents by the labour unions, which then revised and approved the questionnaire and its domains before the pilot study was started. 


\section{Procedures}

The pilot study participants completed four questionnaires (Generic health status score: EQ-5D-5L ${ }^{25}$; back pain disability: Oswestry Disability Index (ODI) ${ }^{26} 27$; Painrelated fear: $\mathrm{FABq}^{28}$ ), and the items identified for $\mathrm{P} 4 \mathrm{Wq}$ development. Responses to the items on the new questionnaire were: never, rarely, sometimes, often or always. Each response was scored from 0 to 4 as follows: 0 -never, 1-rarely, 2-sometimes, 3-often and 4-always. Inversion scoring was applied to the identified items. Participants were excluded if more than $50 \%$ of their responses were missing. The test-retest at 2 weeks ( \pm 1 week) was conducted with 20 randomly selected participants. Written informed consent was requisite for participation in the study.

Statistical data analysis was performed using SPSS (IBM Corp, released 2011, IBM SPSS Statistics, V.20.0). Results are expressed as average $\pm \mathrm{SD}$ and/or $95 \%$ CI. Level of significance was set at $\mathrm{p}<0.05$.

\section{Structural validity}

Only items with a response rate $>50 \%$ were considered for the procedure. Based on the data collected, the index of discrimination was calculated for all items. The discrimination index was estimated based on the correlations between each item and the overall result of the questionnaire. Items with a discrimination index $>0.40$ and an interitem correlation $<0.80$ were entered in the factor analysis.

Bartlett's test of sphericity and Kaiser-Meyer-Olkin (KMO) tests were used to assess adequate sample composition. The dimensionality of the questionnaire was evaluated by conducting an exploratory factor analysis using the VARIMAX method of orthogonal rotation. VARIMAX rotation was used to improve data suitability for factor analysis. Furthermore, a parallel analysis was conducted to set the correct number of domains matching our results with parameters from a random data eigenvalue generator. The number of final factors retained was the number of eigenvalues larger than the corresponding randomly generated eigenvalues. ${ }^{29}$ The final version of the questionnaire was composed of items with higher factor loadings within the subscores.

\section{Internal consistency}

Internal consistency was examined by testing the interitem correlation matrix and calculating Cronbach's $\alpha$ for the whole questionnaire and the single subscores once identified. When internal consistency was low $(\alpha<0.70)$, the reliability was recalculated after removing the items that reduced consistency. A Cronbach's $\alpha$ of $0.7-0.9$ was considered acceptable.

\section{Reliability}

Test-retest reliability was performed to assess the stability of item response after 2 weeks \pm 1 week follow-up in 20 randomly selected participants. To assess the reliability between Likert-like item responses, linear weighted kappa statistics was used. The levels of kappa statistics were: $0.00<\mathrm{K}<0.20$ poor or slight agreement; $0.21<\mathrm{K}<0.40$ fair; $0.41<\mathrm{K}<0.60$ moderate; $0.61<\mathrm{K}<0.80$ substantial or good; $0.81<\mathrm{K}<1.00$ very good or perfect.

\section{Hypotheses testing for construct validity}

The resulting $\mathrm{P} 4 \mathrm{Wq}$ was the sum of all selected items, each of which scored from 0 to 4 . The final step in questionnaire development was the assessment of its convergent validity. The study group expected to find a significant correlation between the $\mathrm{P} 4 \mathrm{Wq}$ and its subscores for indicators of quality of life (EQ-5D-5L), disability (ODI) and work-related pain (FABq work). Spearman's rank correlation or Pearson's correlation were applied to test these hypotheses. A significant although moderate correlation is desirable to establish the new questionnaire as a different tool that expands information on the population. ${ }^{30}$

The $\mathrm{ODI}^{31}$ emerged as the most commonly recommended specific outcome measure for spinal disorders. This self-report questionnaire is composed of ten topics investigating pain intensity, lifting, ability to care for oneself, ability to walk, ability to sit, sexual function, ability to stand, social life, sleep quality and ability to travel. Each item is scored on a scale from 0 to 5 . All item scores are summed, then multiplied by two to obtain the total ODI (range 0-100). Zero denotes no disability and 100 the maximum disability possible.

In 1993, Waddell et $a l^{21}$ developed an FABq to estimate, from a biopsychosocial perspective, how physical activity and work can affect low back pain. The FABq is the sum of 11 items scored from 0 to 6 . Two subscores assess fearavoidance beliefs about physical activity and work, scored from 0 to 36 and 0 to 66 , respectively.

The EQ-5D-5L ${ }^{20}$ was developed as a standardised tool for measuring generic health status. It has been widely used in scientific research for health surveys, clinical studies, economic evaluation and clinical outcome assessment. The instrument has two components: health state description and evaluation. The report is based on five dimensions: mobility, self-care, usual activities, pain/ discomfort and anxiety/depression. Each dimension is scored from 0 to 4 . The health status evaluation section estimates overall health status graded on a visual analogue scale (VAS) from 0 to 100.

\section{Face validity}

Face validity was focused on the instructions, the medical history section, the 20 items of the P4Wq and responses to the questionnaire items. Assessment was performed 6 months after the first round of the full set of item collection. Face validity was assessed involving 20 randomly selected participants. Two separate Likert-like scales were used to evaluate clarity and comprehension. Clarity was evaluated on a 5-point scale from 1 (not clear at all) to 5 (very clear), and comprehension was evaluated on a similar scale from 1 (totally incomprehensible) to 5 (easy to understand). The face validity index was the average index value of these indexes. The results were then 


\begin{tabular}{lc}
\hline \multicolumn{1}{l}{ Table 1} & Study sample demographics \\
\hline Characteristic & $\mathbf{N}=\mathbf{1 1 5}(\%)$ \\
\hline Healthcare & $35(37.4)$ \\
Administration & $37(32.2)$ \\
Ancillary & $41 \pm 9.94$ \\
Age, years & $77(67)$ \\
Women no. (\%) & $7.70 \pm 7.93 / 100$ \\
ODI & $26.65 \pm 21.87 / 66$ \\
FABq & $81.19 \pm 14.75 / 100$ \\
EQ-5D-5L & $0.19 \pm 0.45$ \\
Mobility & $0.08 \pm 0.30$ \\
Self-care & $0.28 \pm 0.48$ \\
Activity & $0.91 \pm 0.79$ \\
Pain & $0.39 \pm 0.63$. \\
Anxiety & $26.07 \pm 12.25 / 80$ \\
P4Wq & $11.44 \pm 6.46$ \\
PSS & $6.56 \pm 4.05$ \\
MMS & $4.51 \pm 3.0$ \\
JSS & $3.56 \pm 3.42$ \\
KCS & \\
\hline
\end{tabular}

Administration, laboratory researchers, concept employees, video terminal workers; EQ-5D-5L, EuroQol 5 dimensions generic health status; FABq, Fear-Avoidance Beliefs Questionnaire; Healthcare, physicians, nurses, radiology technicians, physiotherapists; JSS, Job Satisfaction Subscore; KCS, Kinesiophobia/Catastrophizing Subscore; MSS, Mental Stress Subscore; ODI, Oswestry Disability Index; PPS, Physical Stress Subscore; P4Wq, Prevent for Work Questionnaire.

converted into percentage between 0 (totally unclear or incomprehensive) and $100 \%$ (clear or understandable). According to Polit $e t a l^{2}$ a face validity index $>80 \%$ is considered satisfactory. The time to complete the new questionnaire was recorded for each participant.

\section{Patient and public involvement}

Patients were not involved in the design and conduct of this research. Priorities, experience and preferences of the target population (ie, workers) were not considered forming the aims, data analysis or dissemination of results. We intend to disseminate the main results of this research and will seek patient and public involvement in the development of an appropriate method of dissemination.

\section{RESULTS}

\section{Pilot study}

\section{Participant characteristics}

A total of 162 individuals gave their consent to participate in the study: 47 were excluded because of missing documentation or a response rate $<50 \%(29.1 \%)$. Analysis of the missingness pattern revealed no significant differences. In all, 115 hospital employees $(70.9 \%)$ were enrolled in the study: 38 (33\%) men and 77 (67\%) women, average age $41 \pm 9.94$ years. The sample population breakdown was $43(37.4 \%)$ healthcare workers, 35
$(30.4 \%)$ administrative workers and $37(32.2 \%)$ other workers. Table 1 presents the sample demographics.

\section{Structural validity}

The index of discrimination was $\geq 0.40$ in $52 / 89$ initial questionnaire items, which were used in the next validation step (table 2 and figure 1 ).

Bartlett's test of sphericity and the KMO tests showed adequate sample composition of the items for the factor analysis. After exploratory factor analysis, the parallel analysis identified four factors. For attribution of the items to the factors, the VARIMAX method of orthogonal rotation was used to minimise cross-loading and obtain uncorrelated factor structures. Factor analysis confirmed that the questionnaire was consistent with the biopsychosocial model of interpretation of risk factors on four distinct subscores. After evaluating the content of the subscore items, the study group named them: Physical Stress Subscore (PSS), Mental Stress Subscore (MSS), Job Satisfaction Subscore (JSS) and Kinesiophobia/Catastrophizing Subscore (KCS). The final version included the items with the best factor loading that allowed preserving the weight of each subscore. The P4Wq was composed of 20 items in all (23.d; 24.c; 23.a; 25.a; 27.b; 24.d; 18.d; 16.a; 18.a; 16.b; 18.d; 16.a; 14.c; 16.c 18.a; 16.b; 22.b; 22.a; 22.c; 21.b) and comprising the PSS (six items: 23.d; 24.c; 23.a; 25.a; 27.b; 24.d), the MSS (six items: 18.d; 16.a; 14.c; 16.c 18.a; 16.b), the JSS (four items: 6.c; 12.b; 4.c; 10.b) and the KCS (four items: 22.b; 22.a; 22.c; 21.b) (table 3). Inversion scoring was applied to item 16.b. The total P4Wq score was the sum of all item scores. Each subscore can be calculated separately to obtain more detailed information. The mean P4Wq score was $26.07 \pm 12.25$, the mean PSS was $11.44 \pm 6.46$, the mean MSS was $6.56 \pm 4.05$, the mean JSS was $4.51 \pm 3.0$ and the mean KCS was 3.56 \pm 3.42 .

\section{Internal consistency}

The reliability for the whole $\mathrm{P} 4 \mathrm{Wq}$ and the individual subscales was tested by internal consistency assessment. Cronbach's alpha ranged from 0.81 to $0.91\left(\alpha_{\mathrm{P} 4 \mathrm{Wq}}=0.89\right.$; $\left.\alpha_{\mathrm{PSS}}=0.91 ; \alpha_{\mathrm{MSS}}=0.823 ; \alpha_{\mathrm{JSS}}=0.815 ; \alpha_{\mathrm{KCS}}=0.823\right)$, indicating good internal consistency and that the $\mathrm{P} 4 \mathrm{Wq}$ and its subscores describe the same phenomenon.

\section{Reliability}

The mean test-retest reliability was good to perfect for all items. Weighted kappa coefficients ranged from 0.617 to 1.00 (table 3 ), while the average time between test and retest was 11 days $( \pm 3.79)$.

\section{Hypotheses testing for construct validity}

In the final development stage of the P4Wq, construct evaluation was assessed by convergent validity with previously validated questionnaires. In this sample, the mean $\pm \mathrm{SD}$ ODI was $7.70 \pm 7.93$, the overall FABq $26.65 \pm 21.87$, the FABq Job subscale 16.55 \pm 14.71 , the FABq Physical Activity subscale $12.09 \pm 8.95$, the EQ5 total $81.19 \pm 14.75$, the EQ5 Mobility subscore $0.19 \pm 0.45$, the EQ5 Self-care subscore $0.08 \pm 0.30$, the EQ5 Activity subscore $0.28 \pm 0.48$, the EQ5 
Table 2 Interitem correlation matrix

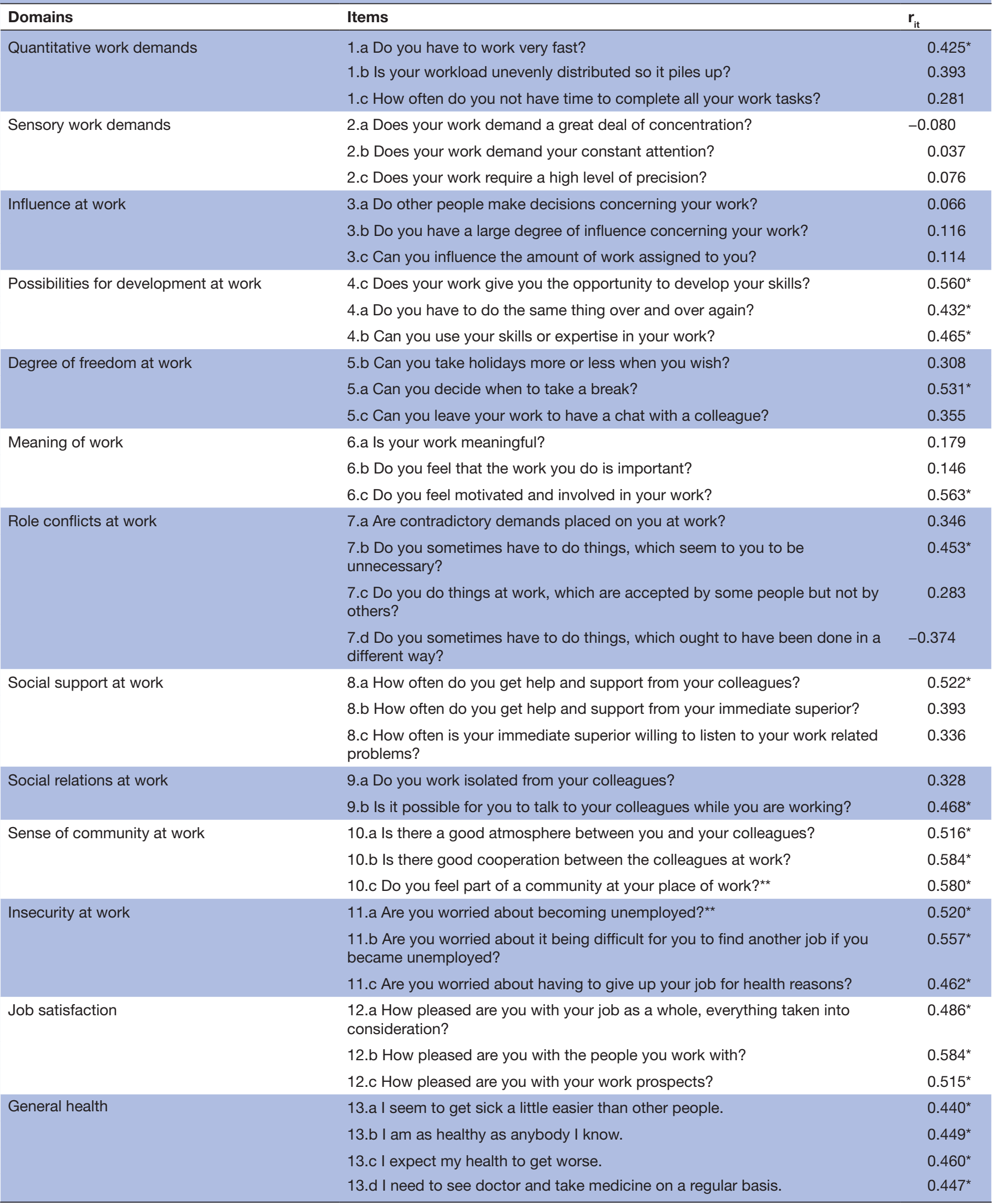

Continued 
Table 2 Continued

Domains Items $\quad r_{\text {it }}$

Mental health

14.a How much of the time during the past 4 weeks have you felt so down in the $0.529^{*}$ dumps that nothing could cheer you up?

14.b How much of the time during the past 4 weeks have you been a very $\quad 0.476^{*}$ nervous person?

14.c How much of the time during the past 4 weeks have you felt calm and peaceful?

\begin{tabular}{|c|c|c|}
\hline \multirow[t]{3}{*}{ Vitality } & $\begin{array}{l}\text { 15.a How much of the time during the past } 4 \text { weeks did you15.a have a lot of } \\
\text { energy? }\end{array}$ & $0.529^{*}$ \\
\hline & 15.b How much of the time during the past 4 weeks did you feel worn out? & $0.429^{*}$ \\
\hline & 15.c How much of the time during the past 4 weeks did you feel tired? & 0.300 \\
\hline \multirow[t]{3}{*}{ Behavioural stress } & 16.a I have difficulty to relax or enjoy myself. & $0.407^{\star}$ \\
\hline & 16.b I have not been able to stand dealing with other people. & $0.439^{*}$ \\
\hline & 16.c I have found it difficult to be happy. & $0.477^{*}$ \\
\hline \multirow[t]{4}{*}{ Somatic stress } & $\begin{array}{l}\text { 17.a How much of the time during the past } 4 \text { weeks have you had stomach } \\
\text { ache or stomach problems? }\end{array}$ & 0.292 \\
\hline & $\begin{array}{l}\text { 17.b How much of the time during the past } 4 \text { weeks have you had a tight chest } \\
\text { or chest pains? }\end{array}$ & 0.266 \\
\hline & $\begin{array}{l}\text { 17.c How much of the time during the past } 4 \text { weeks have you had tension in } \\
\text { various muscles? }\end{array}$ & 0.327 \\
\hline & $\begin{array}{l}\text { 17.d How much of the time during the past } 4 \text { weeks have you had difficulty to } \\
\text { sleep? }\end{array}$ & 0.395 \\
\hline \multirow[t]{4}{*}{ Cognitive stress } & $\begin{array}{l}\text { 18.a How much of the time during the past } 4 \text { weeks have you had problems } \\
\text { concentrating? }\end{array}$ & $0.638^{*}$ \\
\hline & $\begin{array}{l}\text { 18.b How much of the time during the past } 4 \text { weeks have you had difficulty with } \\
\text { remembering? }\end{array}$ & $0.532^{*}$ \\
\hline & $\begin{array}{l}\text { 18.c How much of the time during the past } 4 \text { weeks have you had difficulty in } \\
\text { taking decisions? }\end{array}$ & $0.633^{*}$ \\
\hline & $\begin{array}{l}\text { 18.d How much of the time during the past } 4 \text { weeks have you found it difficult to } \\
\text { think clearly? }\end{array}$ & $0.553^{*}$ \\
\hline \multirow[t]{3}{*}{ Sense of coherence } & 19. a I believe I can cope with most situations in life. & 0.273 \\
\hline & 19.b I feel that what I do in my daily life is meaningful. & 0.385 \\
\hline & 19.c I do not feel that I am able to influence my future to any great extent. & $0.593^{*}$ \\
\hline \multirow[t]{2}{*}{ Problem-focused coping } & 20.a Do you try to find out what you can do to solve the problem? & $0.487^{*}$ \\
\hline & 20.b Do you do anything to solve the problem? & $0.518^{\star}$ \\
\hline \multirow[t]{3}{*}{ Kinesiophobia } & 21.a I'm afraid that I might injure myself if I exercise. & 0.335 \\
\hline & $\begin{array}{l}\text { 21.b Simply being careful that I do not make any unnecessary movements is the } \\
\text { safest thing I can do to prevent my pain from worsening. }\end{array}$ & $0.447^{*}$ \\
\hline & 21.c If I were to try to overcome it, my pain would increase. & $0.460^{*}$ \\
\hline \multirow[t]{3}{*}{ Catastrophizing } & 22. a I become afraid that the pain will get worse. & $0.637^{\star}$ \\
\hline & 22.b I feel I can’t go on. & $0.544^{*}$ \\
\hline & 22.c It's terrible and I think it's never going to get any better. & $0.412^{*}$ \\
\hline \multirow[t]{4}{*}{ Force exertion } & 23.a Do you in your work often have to lift heavy loads (more than $5 \mathrm{~kg}$ )? & $0.531^{*}$ \\
\hline & $\begin{array}{l}\text { 23.b Do you in your work often have to pull or push heavy loads (more than } \\
5 \mathrm{~kg} \text { )?† }\end{array}$ & $0.562^{*}$ \\
\hline & 23.c Do you in your work often have to lift with the load far from the body? $\dagger$ & $0.677^{*}$ \\
\hline & 23.d Do you in your work often have to lift in an awkward posture? & $0.629^{*}$ \\
\hline \multirow[t]{4}{*}{ Dynamic loads } & 24.a Do you in your work often have to bend heavily with your trunk?† & $0.526^{*}$ \\
\hline & 24.b Do you in your work often have to twist heavily with your trunk?† & $0.607^{*}$ \\
\hline & 24.c Do you in your work often have to bent and twist with your trunk? & $0.606^{*}$ \\
\hline & 24.d Do you in your work often have to lift the arms above shoulder height? & $0.612^{*}$ \\
\hline
\end{tabular}

Continued 


\begin{tabular}{|c|c|c|}
\hline Domains & Items & $r_{i t}$ \\
\hline \multirow[t]{4}{*}{ Static loads } & $\begin{array}{l}\text { 25.a Do you in your work often have to work in a heavily bent posture for a } \\
\text { prolonged time? } \dagger\end{array}$ & $0.426^{*}$ \\
\hline & 25.b Do you in your work often have to work in uncomfortable postures? & $0.627^{*}$ \\
\hline & $\begin{array}{l}\text { 25.c Do you in your work often have to work in a heavily twisted posture for a } \\
\text { prolonged time?† }\end{array}$ & $0.467^{*}$ \\
\hline & $\begin{array}{l}\text { 25.d Do you in your work often have to work in a squatting or stooping posture } \\
\text { for a prolonged time? }\end{array}$ & $0.424^{*}$ \\
\hline \multirow[t]{3}{*}{ Repetitive loads } & 26.a Do you in your work often have to work in the same postures? & 0.269 \\
\hline & $\begin{array}{l}\text { 26.b Do you in your work often have to always make the same movements with } \\
\text { your trunk? }\end{array}$ & $0.442^{*}$ \\
\hline & $\begin{array}{l}\text { 26.c Do you in your work often have to make small movements with hands/ } \\
\text { fingers at a high workpace? }\end{array}$ & 0.115 \\
\hline \multirow[t]{3}{*}{ Ergonomic environment } & $\begin{array}{l}\text { 27.a Do you in your work often have to not enough room around you to perform } \\
\text { your work properly? }\end{array}$ & $0.468^{*}$ \\
\hline & $\begin{array}{l}\text { 27.b Do you in your work often have to difficulty in exerting enough force } \\
\text { because of uncomfortable postures? }\end{array}$ & $0.656^{\star}$ \\
\hline & $\begin{array}{l}\text { 27.c Do you in your work often have to not enough room above you to perform } \\
\text { your work without bending? }\end{array}$ & $0.524^{*}$ \\
\hline \multirow[t]{3}{*}{ Vibration } & $\begin{array}{l}\text { 28.a Do you in your work experience noticeable mechanical vibrations or } \\
\text { shocks? }\end{array}$ & $0.562^{*}$ \\
\hline & 28.b Do you carry vibrating tools during your work? & 0.293 \\
\hline & 28.c Do you drive vehicles during your work? & 0.078 \\
\hline
\end{tabular}

The initial pool of 89 items in 28 domains and their index of discrimination (item total) correlation coefficients $\left(\mathbf{r}_{i t}\right)$ for each item after the pilot study. *Items with a discrimination index $>0.40$.

†Interitem correlation $>0.80$. Items with a higher discrimination index were selected for factor analysis to avoid multicollinearity and to have two similar items in the final steps.

Pain subscore $0.91 \pm 0.79$ and the EQ5 Anxiety subscore $0.39 \pm 0.63$.

There was a statistically significant negative association between the P4Wq score and the indicator of quality of life-EQ-5D-5L- $(\mathrm{r}=-0.549, \mathrm{p}<0.001)$ and a significant positive association between disability index-ODI$(\mathrm{r}=0.549, \mathrm{p}<0.001)$ and work-related pain-FABq work$(\mathrm{r}=0.688, \mathrm{p}<0.001)$ (figure 2$)$. For the subscores there was a significant positive association between the KCS items and the EQ5-Pain Subdomain (22.a $\mathrm{r}=0.549, \mathrm{p}<0.001$; 22.b $\mathrm{r}=0.503, \mathrm{p}<0.001$ ), MSS items mostly associated with the EQ5-Anxiety Subdomain (16.b $\mathrm{r}=0.426, \mathrm{p}<0.001$; 16 .c $\mathrm{r}=0.4516, \mathrm{p}<0.001 ; 18 . \mathrm{d} \mathrm{r}=0.436, \mathrm{p}<0.001)$, PSS items mostly associated with the EQ5-Pain Subdomain (24.d $\mathrm{r}=0.333, \mathrm{p}<0.001 ; 27 . \mathrm{b} \mathrm{r}=0.302, \mathrm{p}<0.001)$ and JSS items associated with EQ5-Activity (4.c $\mathrm{r}=0.360$ and 6.c $\mathrm{r}=0.342$, $\mathrm{p}<0.001$ ) and the EQ5-Pain Subdomain (4.c $\mathrm{r}=0.244$, $\mathrm{p}<0.001)$. This moderate although significant correlation provides good evidence for the scale's construct validity.

\section{Face validity}

The universal validity index was $96.04 \%$, clarity was $95.61 \%$ and comprehension was $96.48 \%$. The outcomes indicated consistent face validity results. One item from the KCS, formerly item \#11, ('The most reliable way to prevent my pain from increasing is to make sure I don't make unnecessary movements'.) performed lower on face validity (universal validity index 92\%) and so was improved in the final version. In November 2020, the experts and two professional translators agreed on the final version via forward back translation (Italian to English $\geq$ English to Italian): 'I avoid unnecessary movements to prevent the pain from getting worse'. (From the final original Italian version: 'Evito movimenti non necessari per impedire che il dolore peggiori'.) The median time to complete the P4Wq was 3 min (table 3).

\section{DISCUSSION}

The 20-item P4Wq was developed and validated in this study. Its core construct is based on a biopsychosocial model of WMSDs. As suggested in a previous study, ${ }^{19}$ this approach indicates that the conceptual model for developing a new risk assessment questionnaire for WMSDs should address physical and psychosocial factors.

\section{STRUCTURAL VALIDITY}

To identify hazardous situations that require ergonomic interventions, Hildebrandt $e t$ al designed a comprehensive tool to identify physical stressors in the workplace: the Dutch Musculoskeletal Questionnaire. ${ }^{33}$ Based on global assessment of workload and other potentially hazardous working conditions, the $\mathrm{P} 4 \mathrm{Wq}$ was developed to identify risk groups and to inform experts with data 
Table 3 Factor analysis, item reliability and face validity for selected items

\begin{tabular}{|c|c|c|c|c|c|c|}
\hline \multirow[b]{2}{*}{ Subdomain } & \multirow[b]{2}{*}{ Item number and content } & \multirow{2}{*}{$\begin{array}{l}\text { Kappa value (FV } \\
\text { index \%) }\end{array}$} & \multicolumn{4}{|c|}{ Domains } \\
\hline & & & 1 & 2 & 3 & 4 \\
\hline \multirow[t]{10}{*}{$\begin{array}{l}\text { Physical Stress } \\
\text { Subscore }\end{array}$} & $\begin{array}{l}\text { 23.d Do you in your work often have to } \\
\text { lift in an awkward posture? } \\
(\# 16-P 4 W q)\end{array}$ & $0.860(94.2)$ & 0.803 & & & \\
\hline & $\begin{array}{l}\text { 24.c Do you in your work often have to } \\
\text { bent and twist with your trunk? } \\
\text { (\#17-P4Wq) }\end{array}$ & $0.771(94.2)$ & 0.796 & & & \\
\hline & $\begin{array}{l}\text { 25.b Do you in your work often have to } \\
\text { work in unconformable postures? } \\
\text { (\#19-P4Wq) }\end{array}$ & $0.867(97.6)$ & 0.775 & & & \\
\hline & $\begin{array}{l}\text { 27.b Do you in your work often have } \\
\text { to difficulty in exerting enough force } \\
\text { because of uncomfortable postures? } \\
\text { (\#20-P4Wq) }\end{array}$ & $0.703(94.2)$ & 0.746 & & & \\
\hline & $\begin{array}{l}\text { 24.d Do you in your work often have to } \\
\text { lift the arms above shoulder height? } \\
\text { (\#18-P4Wq) }\end{array}$ & $0.919(95.2)$ & 0.728 & & & \\
\hline & $\begin{array}{l}25 . c \text { Do you in your work often have to } \\
\text { work in a heavily twisted posture for a } \\
\text { prolonged time? }\end{array}$ & 0.635 & 0.692 & & & \\
\hline & $\begin{array}{l}\text { 28.a Do you in your work experience } \\
\text { noticeable mechanical vibrations or } \\
\text { shocks? }\end{array}$ & 1.000 & 0.650 & & & \\
\hline & $\begin{array}{l}\text { 25.d Do you in your work often have to } \\
\text { work in a squatting or stooping posture } \\
\text { for a prolonged time? }\end{array}$ & 0.795 & 0.609 & & & \\
\hline & 5.a Can you decide when to take a break? & 0.706 & 0.474 & & & \\
\hline & 1.a Do you have to work very fast? & 0.767 & 0.406 & & & \\
\hline
\end{tabular}

Mental Stress Subscore 18.d How much of the time during the past 4 weeks have you found it difficult to think clearly? (\#10-P4Wq)

16.a I have difficulty to relax or enjoy myself.

$0.850(94.3)$

(\#6-P4Wq)

14.c How much of the time during the past 4 weeks have you felt calm and peaceful? (\#5-P4Wq)

16.c I have found it difficult to be happy.

(\#8-P4Wq)

18.a How much of the time during the past 4 weeks have you had problems 
Table 3 Continued

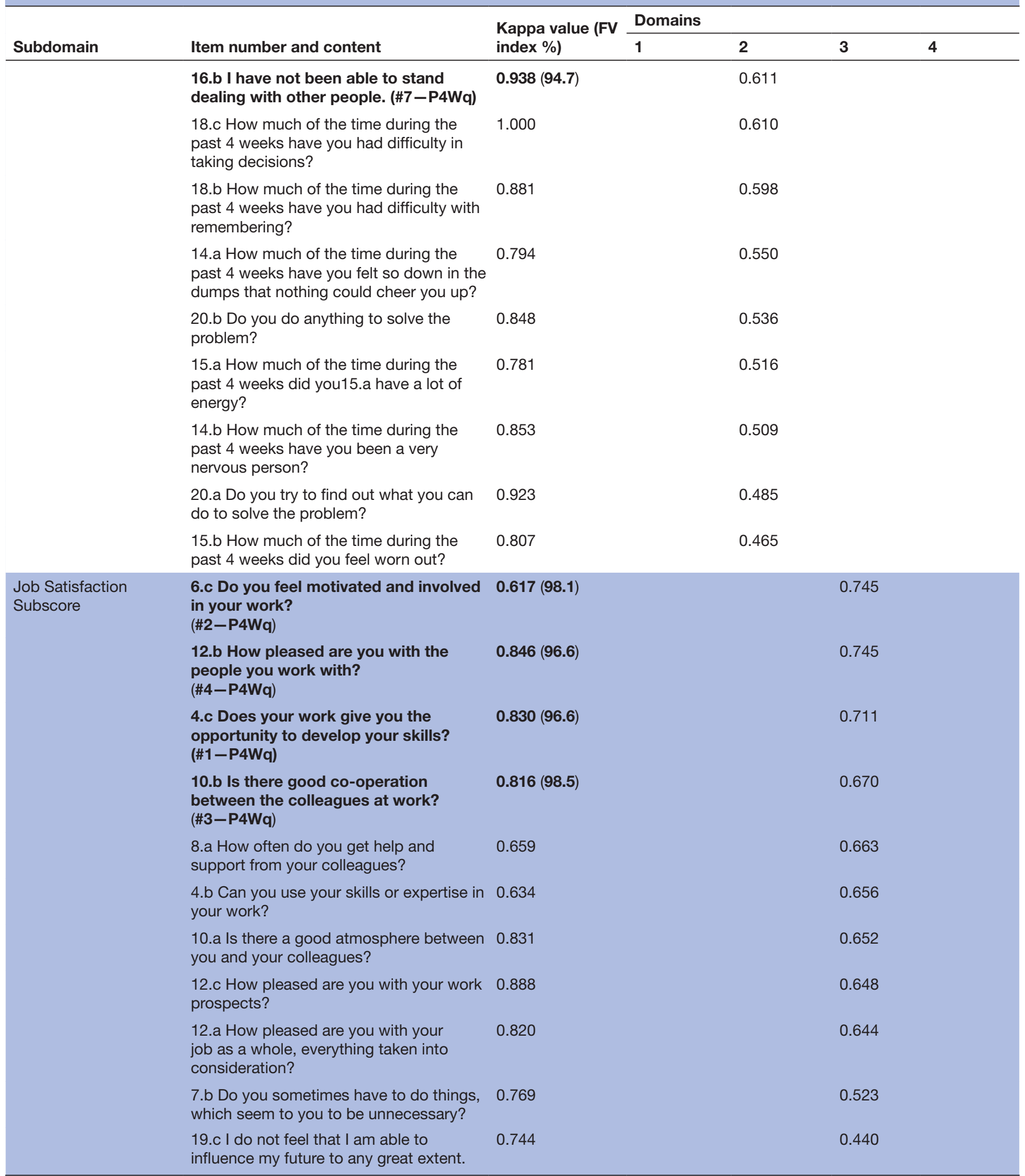

Continued 
Table 3 Continued

\begin{tabular}{|c|c|c|c|c|c|}
\hline \multirow[b]{2}{*}{ Subdomain } & \multirow[b]{2}{*}{ Item number and content } & \multirow{2}{*}{$\begin{array}{l}\text { Kappa value (FV } \\
\text { index \%) }\end{array}$} & \multicolumn{3}{|l|}{ Domains } \\
\hline & & & 2 & 3 & 4 \\
\hline \multirow{11}{*}{$\begin{array}{l}\text { Kinesiophobia and } \\
\text { Catastrophizing } \\
\text { Subscore }\end{array}$} & $\begin{array}{l}\text { 22.b I feel I can't go on. } \\
\text { (\#13-P4Wq) }\end{array}$ & $0.779(95.2)$ & & & 0.802 \\
\hline & $\begin{array}{l}\text { 22.a I become afraid that the pain will } \\
\text { get worse. } \\
(\# 12-P 4 W q)\end{array}$ & $0.913(95.7)$ & & & 0.796 \\
\hline & $\begin{array}{l}\text { 22.c It's terrible and I think it's never } \\
\text { going to get any better. (\#14-P4Wq) }\end{array}$ & $0.839(94.2)$ & & & 0.777 \\
\hline & $\begin{array}{l}\text { 21.b Simply being careful that I do not } \\
\text { make any unnecessary movements is } \\
\text { the safest thing I can do to prevent my } \\
\text { pain from worsening. } \\
\text { (\#11-P4Wq) }\end{array}$ & $0.813(91.9)$ & & & 0.682 \\
\hline & $\begin{array}{l}21 . c \text { If I were to try to overcome it, my } \\
\text { pain would increase. }\end{array}$ & 1.0 & & & 0.676 \\
\hline & $\begin{array}{l}\text { 11.c Are you worried about having to give } \\
\text { up your job for health reasons? }\end{array}$ & 0.910 & & & 0.592 \\
\hline & $\begin{array}{l}\text { 13.d I need to see doctor and take } \\
\text { medicine on a regular basis. }\end{array}$ & 0.948 & & & 0.586 \\
\hline & 13.c I expect my health to get worse. & 0.804 & & & 0.510 \\
\hline & 13.b I am as healthy as anybody I know. & 1.000 & & & 0.488 \\
\hline & $\begin{array}{l}\text { 11.b Are you worried about it being } \\
\text { difficult for you to find another job if you } \\
\text { became unemployed? }\end{array}$ & 0.837 & & & 0.478 \\
\hline & $\begin{array}{l}\text { 13.a I seem to get sick a little easier than } \\
\text { other people. }\end{array}$ & 0.817 & & & 0.457 \\
\hline
\end{tabular}

Extraction method: Principal Component Analysis.

Rotation method: Varimax with Kaiser Normalisation.

Factor analysis results. Given in bold are the items included in the final version of the P4Wq and numeration ( $\mathrm{p}<0.05)$. Kappa value: item reliability at

2 weeks \pm 1 week follow-up. FV index \%: face validity index, the average between clarity and comprehension expressed in percentage.

${ }^{*}$ Rotation converged in five iterations.

P4Wq, Prevent for Work Questionnaire.

to set priorities and apply educational and preventive actions for workers.

In addition to physical factors, the development and persistence of chronic pain correlate with psychological and social risk factors. ${ }^{34}$ There is increasing evidence that psychosocial risk factors play a major role in developing, maintaining or progression to chronic WMSDs. For example, fear-avoidance and catastrophizing ${ }^{35}$ behaviour are characteristic of patients with musculoskeletal disorders, ${ }^{36}$ and questionnaires such as the Tampa Scale of Kinesiophobia $^{37}$ are a good predictor of disability and chronic back pain. ${ }^{38}$ In addition, questionnaires that include the assessment of job stress and satisfaction or emotional and cognitive dimensions, such as the Copenhagen Psychosocial Questionnaire, seem to provide a comprehensive evaluation of more relevant factors at work. ${ }^{39}$ The results of our pilot study laid the basis for the development of a questionnaire that includes assessment of physical factors, mental stress factors, working environment, kinesiophobia and fear-avoidance behaviour.

In their milestone 2003 study, Linton and Boersma presented a multifactorial approach to the detection of WMSDs: the Örebro Musculoskeletal Pain Questionnaire
(ÖMPq). By integrating psychological variables, this instrument demonstrated good prediction of future absenteeism due to sickness. ${ }^{40}$ Despite its widespread endorsement, several limitations were identified in the decades to follow. With our study we wanted to maintain a multifactorial approach to WMSDs while addressing some of the limitations of the original ÖMPq that later studies recognised, such as the lack of rigorous development, ${ }^{41}$ non-validated modifications, ${ }^{42}$ inconsistent wording and factor structure. ${ }^{43}$

Another critical aspect not to be underestimated is that there is no simple relationship between physical and psychosocial risk factors and musculoskeletal disorders. Recent evidence suggests that it is essential to apply a systematic approach to identifying these factors in the workplace and the specific problems of workers. ${ }^{44}$ There is a well-known link between the incidence of WMSDs and the working environment, specifically for physical risk factors. ${ }^{2}$ Furthermore, synergies between risk factors (eg, stress and work intensification) and psychosocial factors can contribute to the onset of such disorders. In addition to risk factors related to the working environment, the intrinsic aspect of workers not directly related to work may also contribute to WMSDs. Such 


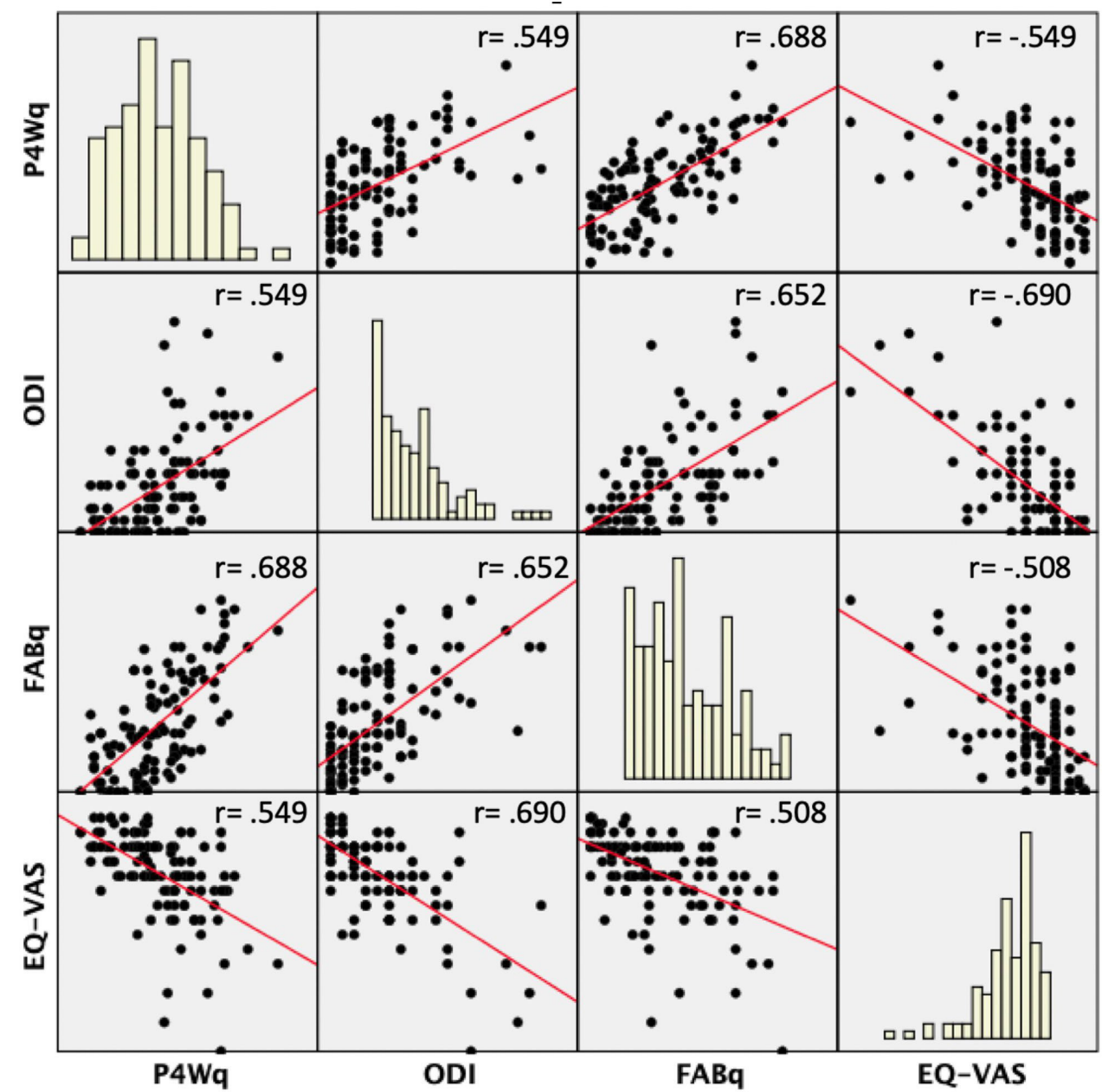

Figure 2 Pearson's correlation for a negative association with the indicator of the quality of life (EQ-5D-VAS (EuroQol Group General health status score-Visual Analogue Scale)) and a positive association with disability index (ODI (Oswestry Disability Index)) and work-related pain (FABq (Fear-Avoidance Beliefs Questionnaire)). The associations are statistically significant for all variables (two-tailed, $\mathrm{p}<0.001$ ). P4Wq, Prevent for Work Questionnaire.

a wide variety of factors may explain the difficulties often encountered in taking a systematic approach to WMSDs and the best intervention to adopt. Furthermore, individual responses can vary widely. Based on a literature review and Delphi study, three groups of risk factors are: physical, psychosocial and individual factors. ${ }^{19}$

In this perspective, the 20-item questionnaire showed that its psychometric properties meet the minimum standards for PROMs set forth by the International Society for Quality of Life Research, ${ }^{45}$ demonstrating good content validity, internal reliability consistency, construct validity and responsiveness. Factorial data analysis identified four subscales: PSS (six items), MSS (six items), JSS (four items) and the KCS (four items). The P4Wq is currently available in Italian (online supplemental appendix A) and English (online supplemental appendix B). Other translations are freely available online (https://p4work.com/results/).

In addition, structural validity showed that the psychological weight of workers was relevant. Healthcare workers are under continuous pressure and work in high complexity structures where the primary aim is to deliver high-quality care. Evaluation of the interaction between risk factors is fundamental, especially in this group of workers, rather than focus on only one factor. For this reason, a high P4Wq score does not necessarily indicate that the worker experiences pain or disability due to a WMSD but rather that there is a theoretically increased risk of developing one in the future.

\section{CONSTRUCT VALIDITY}

The study indicated that the questionnaire is valid, applicable and can be useful in the analysis of risk factors for WMSDs. Comparative analysis between the $\mathrm{P} 4 \mathrm{Wq}$ and validated questionnaires (ODI, FABq, EQ-5D-5L) identified a key correlation that provides strong evidence for its construct validity. The behaviour of the total P4Wq score showed a direct correlation with the ODI disability score and an inverse correlation with the EQ-5D-5L quality of life score. Workers scoring high on the $\mathrm{P} 4 \mathrm{Wq}$ are at greater risk if they have a WMSD. The diagnostic, predictive and risk stratification capabilities of the $\mathrm{P} 4 \mathrm{Wq}$ need to be explored in future studies. Based on the analysis in this sample, the $\mathrm{P} 4 \mathrm{Wq}$ seems to overcome the floor effect of the ODI and the ceiling effect of the EQ-5D-VAS. This raises optimism for its ability to stratify otherwise healthy 
workers and to detect WMSDs, which will be an area of focus for future studies. In addition, as a tool that stratifies risks, the P4Wq and collaboration between academia, work healthrelated institutions and health technology companies can lead to the development of innovative preventive strategies against WMSDs.

\section{Methodological considerations and limitations}

One limitation of this study is that the P4Wq involved employees at a single centre where most were healthcare workers. The aim of the instrument is to address generic issues in a variety of settings rather than to a specific healthcare centre. The construct validity of the $\mathrm{P} 4 \mathrm{Wq}$ was evaluated using two questionnaires (ODI and FABq) that were developed to evaluate patients with back pain. It is possible, therefore, that the current validation process is to a lesser extent transferrable to WMSDs in other anatomical regions.

Nearly all participants were Caucasian and participated voluntarily in the study, which may have created a selection bias limiting generalisability. A further limitation is the inadequate sample size to evaluate test-retest reliability. A sample of 30 participants would be preferable for such purposes. ${ }^{24}$ To date, the P4Wq has not been evaluated for its potential diagnostic and predictive capabilities in musculoskeletal disorders. This will be the focus of future studies. Also, further work is desirable to validate the questionnaire in other populations and languages. High-quality studies with a larger sample size and longer follow-up period are needed to consolidate the knowledge so far acquired, assess the predictive capabilities of the questionnaire and curtail some of the bias of the present study.

\section{CONCLUSIONS}

The aim of this study, derived from a literature review and a Delphi consensus, was to develop the P4Wq. The domains and items define a conceptual framework consistent with a biopsychosocial model of disease and the fear-avoidance components of chronic pain. The P4Wq has four subscales: PSS, MSS, JSS and KCS. It provides a concise measure of risk factors for work-related back disorders that have demonstrated good content validity, construct validity, internal consistency reliability and high face validity. For the methodological approach used and its intrinsic limitations, the questionnaire specifically assesses back disorders, and this aspect limits generalisability to all WMSDs. Further studies are needed to assess the ability of the P4Wq to predict WMSDs occurrence or progression to chronicity.

\section{Author affiliations}

${ }^{1}$ IRCCS Istituto Ortopedico Galeazzi, Milan, Italy

${ }^{2}$ Department of Health Science and Technology, Aalborg University, Aalborg, Denmark

${ }^{3}$ Department of Physiotherapy, University College of Northern Denmark, Aalborg, Denmark

${ }^{4}$ Department of Physiotherapy, Faculty of Health Sciences, Universidad San Jorge, 50830 Villanueva de Gállego, Zaragoza, Spain

${ }^{5}$ IRCCS Fondazione Don Carlo Gnocchi, Milan, Italy

${ }^{6}$ Department of Physiatry and Nursing, Faculty of Health Sciences, University of Zaragoza, Zaragoza, Aragón, Spain
Twitter Thorvaldur Skuli Palsson @tspalsson, Steffan Wittrup McPhee Christensen @SW_Christensen, Priscila de Brito Silva @pribsilva and Victor Domenéch-García @_Victordomenech

Acknowledgements The study group thanks the employees of the IRCCS Istituto Ortopedico Galeazzi (Milan, Italy) for voluntary participation in the study and for their extraordinary work.

Contributors All authors contributed to the study design and met the requirements of the International Committee of Medical Journal Editors (ICMJE). Author contribution varied in the different phases of the project: FL, DV and PBerjano were involved in all phases. PB-L, PH, PBerjano, FL and DV contributed to study conception, design and planning. PBarletta, DV and FL contributed to data collection, and FL, DV and PB-L were responsible for data analysis. Data interpretation and manuscript writing were led by FL, PBerjano and DV with support from PB-L, VD-G, JHV, TSP, MH, PdBS, SWC, PH and PSJ. FL was the responsible for the overall content as the guarantor.

Funding This study was funded by Erasmus+ Programme (agreement no. 2018-2381/001-001, project no. 600920-EPP-1-2018-1-ES-EPPKA2-KA) and the Italian Ministry of Health (agreement no. not applicable).

Disclaimer The funding body had no influence on the outcome or interpretation of findings.

Competing interests None declared.

Patient consent for publication Consent obtained directly from patient(s)

Ethics approval This study involves human participants and was approved by The local Medical Research Ethics Committee reviewed the protocol and approved the study (first version of the WMSDs questionnaire protocol n.174/int/2019 issued on 07/11/2019). All procedures were conducted according to the tenets of the Declaration of Helsinki. Participants gave informed consent to participate in the study before taking part.

Provenance and peer review Not commissioned; externally peer reviewed.

Data availability statement Data are available upon reasonable request. Data can be made available at reasonable request via the corresponding author.

Supplemental material This content has been supplied by the author(s). It has not been vetted by BMJ Publishing Group Limited (BMJ) and may not have been peer-reviewed. Any opinions or recommendations discussed are solely those of the author(s) and are not endorsed by BMJ. BMJ disclaims all liability and responsibility arising from any reliance placed on the content. Where the content includes any translated material, BMJ does not warrant the accuracy and reliability of the translations (including but not limited to local regulations, clinical guidelines, terminology, drug names and drug dosages), and is not responsible for any error and/or omissions arising from translation and adaptation or otherwise.

Open access This is an open access article distributed in accordance with the Creative Commons Attribution Non Commercial (CC BY-NC 4.0) license, which permits others to distribute, remix, adapt, build upon this work non-commercially, and license their derivative works on different terms, provided the original work is properly cited, appropriate credit is given, any changes made indicated, and the use is non-commercial. See: http://creativecommons.org/licenses/by-nc/4.0/.

\section{ORCID iDs}

Francesco Langella http://orcid.org/0000-0002-8639-8480

Thorvaldur Skuli Palsson http://orcid.org/0000-0002-4418-0133

Pablo Bellosta-López http://orcid.org/0000-0003-4750-9077

Jorge Hugo Villafañe http://orcid.org/0000-0002-3239-7626

Priscila de Brito Silva http://orcid.org/0000-0002-5879-3600

Pablo Herrero http://orcid.org/0000-0002-9201-0120

Victor Domenéch-García http://orcid.org/0000-0002-7007-0368

\section{REFERENCES}

1 Barbe MF, Barr AE. Inflammation and the pathophysiology of work-related musculoskeletal disorders. Brain Behav Immun 2006;20:423-9.

2 Crawford JO, Giagloglou E, Davis A. Working with chronic musculoskeletal disorders. Good Practice Advice 2020.

3 European Agency for Safety and Health at Work (EU-OSHA). Improving compliance with occupational safety and health regulations : an overarching review. European Risk Observatory 2021.

4 Parent-Thirion A, Biletta I, Cabrita J. Sixth European working conditions survey - overview report. Eurofound - Update 2019, 2017. 
Available: https://www.eurofound.europa.eu/publications/report/ 2016/working-conditions/sixth-european-working-conditions-surveyoverview-report

5 van den Heuvel S, van der Zwaan L, van Dam L. Estimating the cost of work-related accidents and ill-health: an analysis of European data sources. European Agency for Safety and Health at Work.

6 Bevan S. Economic impact of musculoskeletal disorders (MSDs) on work in Europe. Best Pract Res Clin Rheumatol 2015;29:356-73.

7 Linton SJ, Halldén K. Can we screen for problematic back pain? A screening questionnaire for predicting outcome in acute and subacute back pain. Clin J Pain 1998;14:209-15

8 Arvidsson I, Gremark Simonsen J, Lindegård-Andersson A, et al. The impact of occupational and personal factors on musculoskeletal pain - a cohort study of female nurses, sonographers and teachers. BMC Musculoskelet Disord 2020;21:621.

9 Luttmann A, Jäger M, Griefahn B. Preventing musculoskeletal disorders in the workplace, 2003. Available: http://apps.who.int/iris/ handle/10665/42651

10 Sanderson K, Andrews G. Common mental disorders in the workforce: recent findings from descriptive and social epidemiology. Can J Psychiatry 2006;51:63-75.

11 Moen P, Kelly EL, Lam J. Healthy work revisited: do changes in time strain predict well-being? J Occup Health Psychol 2013;18:157-72.

12 Harvey SB, Sellahewa DA, Wang M-J, et al. The role of job strain in understanding midlife common mental disorder: a national birth cohort study. Lancet Psychiatry 2018;5:498-506.

13 EU-OSHA. Strategies to tackle musculoskeletal disorders at work: training, 2015. Available: https://oshwiki.eu/wiki/Strategies_to_ tackle_musculoskeletal_disorders_at_work:_training

14 Loisel P, Buchbinder R, Hazard R, et al. Prevention of work disability due to musculoskeletal disorders: the challenge of implementing evidence. J Occup Rehabil 2005;15:507-24.

15 Rosenberg NR, Petersen SB, Begtrup LM, et al. Early occupational intervention for people with low back pain in physically Demanding jobs: 1-year follow-up results of the randomized controlled GOBACK trial. Spine 2021;46:347-55

16 Kristman VL, Lowey J, Fraser L, et al. A multi-faceted community intervention is associated with knowledge and standards of workplace mental health: the superior mental wellness @ work study. BMC Public Health 2019;19:638.

17 Kristman VL, Shaw WS, Boot CRL, et al. Researching complex and multi-level workplace factors affecting disability and prolonged sickness absence. J Occup Rehabil 2016;26:399-416.

18 Palsson TS, Boudreau S, Høgh M, et al. Education as a strategy for managing occupational-related musculoskeletal pain: a scoping review. BMJ Open 2020;10:e032668.

19 Langella F, Christensen SWM, Palsson TS, et al. Development of the prevent for work questionnaire (P4Wq) for assessment of musculoskeletal risk in the workplace: part 1-literature review and domains selection. BMJ Open 2021:11:e043800.

20 Group The Euroqol. EuroQol - a new facility for the measurement of health-related quality of life. Health Policy 1990;16:199-208.

21 Waddell G, Newton M, Henderson I, et al. A Fear-Avoidance beliefs questionnaire (FABQ) and the role of fear-avoidance beliefs in chronic low back pain and disability. Pain 1993;52:157-68.

22 Kuorinka I, Jonsson B, Kilbom A, et al. Standardised Nordic questionnaires for the analysis of musculoskeletal symptoms. App/ Ergon 1987; 18:233-7.

23 von Elm E, Altman DG, Egger M, et al. The strengthening the reporting of observational studies in epidemiology (STROBE) statement: guidelines for reporting observational studies. Int J Surg 2014;12:1495-9.

24 Prinsen CAC, Vohra S, Rose MR, et al. Core Outcome Measures in Effectiveness Trials (COMET) initiative: protocol for an international Delphi study to achieve consensus on how to select outcome measurement instruments for outcomes included in a "core outcome set". Trials 2014;15:247.

25 Scalone L, Cortesi PA, Ciampichini R. Health related quality of life norm data of the general population in Italy: results using the EQ5D-3L and EQ-5D-5L instruments. Epidemiol Biostat Public Heal $2015 ; 12$.
26 Monticone M, Baiardi P, Vanti C, et al. Responsiveness of the Oswestry disability index and the Roland Morris disability questionnaire in Italian subjects with sub-acute and chronic low back pain. Eur Spine J 2012;21:122-9.

27 Langella F, Barletta P, Baroncini A, et al. The use of electronic PROMs provides same outcomes as paper version in a spine surgery registry. results from a prospective cohort study. Eur Spine $J$ 2021;30:2645-53.

28 Monticone M, Baiardi P, Bonetti F, et al. The Italian version of the Fear-Avoidance beliefs questionnaire (FABQ-I): cross-cultural adaptation, factor analysis, reliability, validity, and sensitivity to change. Spine 2012;37:E374-80.

29 Patil VH, Surendra NS, Sanjay M. Parallel analysis engine to aid in determining number of factors to retain using $\mathrm{R}$ [Computer software], 2017. Available: https://analytics.gonzaga.edu/ parallelengine/

30 Potocka A, Najder A. Development and validation of the eating maturity questionnaire: preliminary findings. $J$ Health Psychol 2016;21:2294-305.

31 Fairbank JC, Pynsent PB. The Oswestry disability index. Spine 2000;25:2940-53.

32 Polit DF, Beck CT, Owen SV. Is the CVI an acceptable indicator of content validity? Appraisal and recommendations. Res Nurs Health 2007;30:459-67.

33 Hildebrandt VH, Bongers PM, van Dijk FJH, et al. Dutch musculoskeletal questionnaire: description and basic qualities. Ergonomics 2001;44:1038-55.

34 Ortego G, Villafañe JH, Doménech-García V, et al. Is there a relationship between psychological stress or anxiety and chronic nonspecific neck-arm pain in adults? A systematic review and metaanalysis. J Psychosom Res 2016;90:70-81.

35 Sullivan MJL, Bishop SR, Pivik J. The pain catastrophizing scale: development and validation. Psychol Assess 1995;7:524-32.

36 Vlaeyen JWS, Linton SJ. Fear-avoidance and its consequences in chronic musculoskeletal pain: a state of the art. Pain 2000;85:317-32

37 Roelofs J, Sluiter JK, Frings-Dresen MHW, et al. Fear of movement and (re)injury in chronic musculoskeletal pain: Evidence for an invariant two-factor model of the Tampa Scale for Kinesiophobia across pain diagnoses and Dutch, Swedish, and Canadian samples. Pain 2007;131:181-90

38 Goubert L, Crombez G, Van Damme S. Confirmatory factor analysis of the Tampa scale for Kinesiophobia: invariant two-factor model across low back pain patients and fibromyalgia patients. Clin $J$ Pain;20:103-10.

39 Kristensen TS, Hannerz H, Høgh A, et al. The Copenhagen psychosocial questionnaire-a tool for the assessment and improvement of the psychosocial work environment. Scand J Work Environ Health 2005;31:438-49.

40 Linton SJ, Boersma K. Early identification of patients at risk of developing a persistent back problem: the predictive validity of the Örebro musculoskeletal pain questionnaire. Clin J Pain 2003;19:80-6

41 Gabel CP, Melloh M, Yelland M, et al. Predictive ability of a modified Örebro musculoskeletal pain questionnaire in an acute/subacute low back pain working population. Eur Spine J 2011;20:449-57.

42 Margison DA, French DJ. Predicting treatment failure in the subacute injury phase using the Orebro musculoskeletal pain questionnaire: an observational prospective study in a workers' compensation system. J Occup Environ Med 2007;49:59-67.

43 Grotle M, Vøllestad NK, Brox Jl. Screening for yellow flags in firsttime acute low back pain: reliability and validity of a Norwegian version of the acute low back pain screening questionnaire. Clin $J$ Pain 2006;22:458-67.

44 Epstein S, Sparer EH, Tran BN, et al. Prevalence of work-related musculoskeletal disorders among surgeons and interventionalists: a systematic review and meta-analysis. JAMA Surg 2018;153:e174947.

45 Reeve BB, Wyrwich KW, Wu AW, et al. ISOQOL recommends minimum standards for patient-reported outcome measures used in patient-centered outcomes and comparative effectiveness research. Qual Life Res 2013;22:1889-905. 